\title{
Perspectives from physiotherapy supervisors on student-patient communication
}

\author{
Robyn Woodward-Kron1, Diana van Die², Gillian Webb³, John Pill², Catherine Elder², \\ Tim McNamara², Elizabeth Manias ${ }^{3}$, Geoff McColl1 \\ ${ }^{1}$ Medical Education Unit, University of Melbourne, Australia \\ ${ }^{2}$ Language Testing Research Centre, University of Melbourne, Australia \\ ${ }^{3}$ Melbourne School of Health Sciences, University of Melbourne, Australia
}

Correspondence: Robyn Woodward-Kron, Medical Education Unit, 202 Berkeley St, University of Melbourne, Parkville, Victoria 3010, Australia. Email: robynwk@unimelb.edu.au

\begin{abstract}
Objectives: To explore what Australian physiotherapy educators value in student-patient clinical communication by investigating their feedback on physiotherapy students' communication with patients in practice settings. These findings were compared to the national standard descriptors.

Methods: A qualitative study design incorporated delayed time feedback elicited in two workshops from 12 participants who viewed video recorded interactions as triggers for discussion, and real time feedback observed in a hospital setting of 14 clinical supervisors and their students. Both sets of feedback were audio-recorded, transcribed and analysed thematically.

Results: The findings identified five major themes in the clinical supervisor and educators' feedback: non-verbal communication, manner, language, content and organisa-
\end{abstract}

tion, and interactional tools. In the findings, several of the themes resonate with those espoused in available communication frameworks. The findings provide examples of the framework descriptors.

Conclusions: The findings provide important information about the communication skills, attitudes and behaviours that are valued by clinical supervisors and educators. The findings can be used to inform standard setting and curriculum development. Knowledge gained about students' communication skills in practice settings can assist in enhancing communication between physiotherapy students and patients, and it can ultimately contribute to improving patient safety and treatment outcomes.

Keywords: Communication skills, physiotherapy education, physiotherapy students, physiotherapy standards, feedback

\section{Introduction}

Effective communication skills are fundamental for accurately and efficiently gathering information in health professional consultations as well as for addressing the needs and concerns of patients. In rehabilitation and other discharge settings, good communication is essential for patients' understanding of their follow-up care and management. ${ }^{1}$ Poor communication skills impact on patient safety and quality of care while good communication is an important factor in patient satisfaction., ${ }^{2,3}$ In Australian hospitals, poor communication remains an ongoing cause of patient complaint and litigation. ${ }^{4}$ It is the second most common category of complaint received by the NSW Health Care and Patient Complaint Commission in 2010-
2011. ${ }^{5}$ Similar findings about the link between poor communication and adverse patient outcomes have been reported in the United Kingdom. ${ }^{6}$ Another important consideration for teaching and learning clinical communication in Australia and internationally is the cultural diversity of the patient population, health professional students as well as the health workforce. ${ }^{7-11}$ Communication challenges can occur between patients and clinicians, and among health professionals when there are differences in language, culture and socio-economic backgrounds. ${ }^{12,13}$

Health professional educators have an ongoing task of raising students' awareness of the benefits of good communication for patient outcomes. They also need to prepare 
students so that they can overcome some of the above named communication challenges in healthcare delivery. An additional factor is alerting students to the communication demands of their profession. In physiotherapy, communication skills are central to engaging patients in the therapeutic relationship, particularly in chronic care settings. Communication skills which aim to involve patients in their care have also been demonstrated to improve physiotherapy patient outcomes. ${ }^{14}$ Expert physiotherapists value a patient-centred approach to care, in which patients are active participants in decision-making. ${ }^{15}$ Other valued aspects of physiotherapy communication are establishing patients' needs, including their psychosocial needs, ${ }^{3}$ and negotiating treatment goals. ${ }^{16}$ In addition, patient education is seen as integral to effective physiotherapy practice as informed patients are more likely to actively engage with their treatment plans and "remember them [the exercises] and incorporate them during the day". ${ }^{15}$ Similarly, communicating the physical therapist's clinical reasoning to the patient is seen to assist patients to make informed decisions about their treatment. ${ }^{17}$

Communication skills training is now a central component of health professional ${ }^{18}$ and medical school curricula. ${ }^{18-}$ ${ }^{22}$ It is increasingly required by accreditation bodies such as the Institute of International Medical Education as a component of courses. ${ }^{23}$ The Australian Medical Council (AMC) includes communication skills as an element of medical school curricula requiring comprehensive coverage $^{24}$ while in postgraduate training, communication competencies are a cornerstone of the Australian Junior Doctor Curriculum Framework ${ }^{25}$ for early postgraduate doctors. Similar developments are evident in physiotherapy education. Internationally, communication skills are required as part of core competencies, for example in New Zealand, ${ }^{26}$ and in the United Kingdom. ${ }^{27}$ In Australia, effective communication is one of the nine physiotherapy standards required for entry level practitioners. ${ }^{28}$

The Australian physiotherapy standards were developed by the Australian physiotherapy council in consultation with Australian physiotherapists and accepted by the profession in 2006. The standards are a benchmark for the knowledge, skills and attributes that entry-level physiotherapists are expected to have achieved at the completion of their training. Standard 2 is 'communicate effectively'. This standard has five sub domains. The sub-domain that is relevant to this study is: (2.1) communicate effectively with the client. The Australian physiotherapy council points out that the proposed strategies for effective communication are not intended to be an inclusive or exclusive checklist, yet the suggested strategies provide little concrete guidance for educators seeking to enhance or assess students' communication skills. No suggestions or examples are given to exemplify how students might adapt communication "in recognition of the impact of language, culture, abilities, age, gender and/or health status". Furthermore, there is no indication of what the "commonly used communication strategies" are that could assist students to conduct interviews, outline interventions and to give instructions to patients. Without further explication of these standards, it is questionable what value and guidance they can ultimately provide for educators.

In medical education, there have been a vast number of studies on students' clinical communication. These include studies on curriculum content and pedagogy, ${ }^{19}$ documentation of deteriorating communication skills once students are exposed to the clinical environment, ${ }^{29}$ attitudes to communication skills teaching, ${ }^{30}$ assessment, ${ }^{31}$ and evaluation of teaching innovations ${ }^{32}$ (due to space considerations, only one reference has been cited for each area of research). In comparison, there is little corresponding literature in the field of physiotherapy. A scoping study ${ }^{18}$ of United Kingdom physiotherapy centres delivering qualifying programmes identified a need for more experiential teaching and observing of communication skills with patients. There is little detail in available research, either in Australia or internationally, about the critical components of communication in the physiotherapy context. There is also little research evidence on how these components can be translated to physiotherapy communication skills teaching. Furthermore, in Australian healthcare practice, ongoing concerns about poor communication skills and the implications for patient safety and quality healthcare mean that communication skills teaching warrants greater attention. The cultural diversity of Australian patients and the Australian healthcare workforce poses considerable communication challenges for new graduates.

The current study takes an initial step towards filling this gap in published research by focussing on the feedback Australian physiotherapy educators give to students on their communication skills. Our main aim was to identify the themes emerging from this feedback and to examine what these themes revealed about the educator perspective on key features of student-patient communication in the clinical context. We also aimed to elaborate the notion of effective communication as articulated in the Australian physiotherapy standard 2.1, which, to our knowledge, has no empirical basis.

\section{Methods}

This study adopted a qualitative design comprising focus groups and observations to investigate physiotherapy educators' and supervisors' views on effective student communication with patients. The study is part of a larger project relating to a specific purpose English language screening test for overseas-trained health professionals. The aim of the larger study is to validate the criteria against which candidates are assessed on this test, and the performance standards required for registration in Australia. ${ }^{33}$

For the physiotherapy component of the study, ethics approval was gained for the study by the Human Ethics 
Advisory Group at the University of Melbourne, and from the Austin Health Non-Drug Study Ethics Committee. Informed written consent was obtained from all participants.

\section{Participants and data}

The study sought to elicit from physiotherapy educators and clinical supervisors what they valued as effective student-patient communication. The physiotherapy educators and clinical supervisors included in this study were experienced at assessing and providing feedback in the final year of their physiotherapy training. While other studies have investigated differences between experienced and less experienced physiotherapists' perceptions of expertise, ${ }^{15}$ this study focussed on educator and clinical supervisor perceptions of effective student-patient communication. In other words, our interest was in identifying what the educators and supervisors valued in terms of effective student communication with patients rather than differentiating between expert and novice perceptions and their skills. The data for the study are the supervisors and educators' feedback on student-patient communication. Their feedback was seen as a means of capturing the "indigenous criteria" ${ }^{34}$ or context relevant criteria that underlie their professional judgements of the students' communication. Two types of feedback were elicited from the participants. These are explained and justified below.

\section{Data collection}

The study had two phases: the first involving the conduct of workshops, and the second involving the capture of feedback sessions with clinical supervisors and educators in actual practice. In phase one, we conducted two workshops of one-hour duration. In each workshop we showed the physiotherapy educators video recordings of students interacting with patients in both a simulated and a clinical setting. The video recordings provided the trigger to elicit the participating educators' and supervisors' perspectives on aspects of effective and less effective communication viewed in the videos. The educators' and supervisors' audiorecorded responses constituted the data from the workshops. The workshop setting was a controlled setting as each workshop participant was asked to provide feedback on the communication shown in the trigger video. In other words, the workshop approach was guaranteed to generate data on the educators' and supervisors' perspectives of the student communication skills. However, the disadvantage of the controlled setting was that the educator and supervisor perspectives were elicited indirectly rather than in the context of direct feedback to the student. Indirect feedback may focus overtly on communication aspects that may attract less attention or be ignored in the authentic clinical feedback setting. ${ }^{35}$ For this reason, a setting that allowed the capture of authentic feedback to students was investigated in the second phase of the study to ensure collection of data focussing on communication aspects. While both settings 168 sought to capture the "indigenous criteria" ${ }^{4}$ or context relevant criteria that underlie the physiotherapists judgments of communication, the second data collection phase sought to capture authentic clinical supervisor feedback to individual students after they had concluded their interactions with the patient. Both formative and summative feedback was collected in the second phase.

\section{Phase one: workshops}

\section{Phase one: setting and participants}

In phase 1, the first workshop was held in a department of physiotherapy at a university in Melbourne, Australia; the second workshop was held in a large metropolitan teaching hospital affiliated with the university where students undertake clinical placements. The participants were physiotherapy clinical supervisors or academics affiliated with either the university or hospital. There were twelve participants in total: seven attended the university-based workshop and five attended the hospital-based workshop. All participants had at least five years of clinical practice and were experienced assessing students in the clinical setting. The hospital based participants were from a variety of settings, including outpatients, the cardio-respiratory in-patient ward, orthopaedics, and rehabilitation. We invited the participants via email to participate in the workshops.

\section{Phase one: materials}

The triggers for the educator feedback were three video recordings of students interacting with patients in the hospital setting. We showed the participants an excerpt of a video recording of performance from physiotherapy students. The excerpt was between 4 and 8 minutes duration. In the first, an overseas born student with near native English fluency ('Sam') conducted a clinical interview with a patient ('Tony') scheduled for surgery for chronic lower back pain. The second stimulus video recording differed in the two settings: at the university workshop, a native English speaking male student, 'Robert', was attending an elderly female ('Rose'), who had returned to the hospital outpatients for follow-up. Participants at the hospital workshop observed a native English speaking female student ('Brooke') interviewing a patient in a wheelchair ('Bill') who had suffered from stroke and who was attending the rehabilitation unit. The three students shown on the video excerpts were in the final year of their physiotherapy degree.

\section{Phase one: procedure}

Participants were asked by one of the researchers who acted as the workshop facilitator to consider what aspects of each performance they would comment on in a post-observation feedback session; participants were provided with a proforma for note taking while listening to the interactions. The proforma had the sub-headings effective and less effective aspects. The facilitator then asked each participant to 
comment on the performance; this was followed by a general discussion on the candidates' performances. We collected the participants' written notes and we also collected the field notes of the researchers in attendance.

Phase one: analysis

We recorded and transcribed the workshop discussion verbatim. Thematic content analysis was initially undertaken by one of the researchers working independently to identify the indigenous criteria for effective communication skills underlying the supervisors' feedback. The thematic content analysis was informed by categories identified in the data from the medical component of the larger study ${ }^{33}$ and the nursing data. The coding process was an iterative one, in which the coders worked independently on their respective disciplinary data sets (i.e. medicine, nursing, physiotherapy), then met to discuss and compare findings once initial emerging themes had been identified. Three meetings were held to discuss the identification and labelling of themes. A final meeting was held to present the themes to the full research team for discussion. The themes were discussed until there was consensus. In these meetings, co-occurrence in the data of themes was noted as well any relationships or hierarchies between the themes.

\section{Phase two: feedback to students in the clinical setting}

Phase two involved recording physiotherapy studentpatient interactions and supervisor-student feedback in situ. The oral feedback given by supervisors during or following the consultations and feedback sessions constituted the data for the study.

\section{Phase two: setting and participants}

Student-patient and supervisor-student interactions were audio-recorded at the teaching hospital in a variety of settings, including the cardiothoracic and neurology wards, the outpatient clinic, rehabilitation clinic and gymnasium. The participating students were in the final year of their Bachelor course. Across five different settings, a total of 16 physiotherapy students, 11 patients and 11 supervisors were audio-recorded. In addition, the end-of-term placement feedback to students was audio-recorded for 7 students from 3 supervisors, based on performances in the intensive care unit (4 students), and cardiothoracic and neurology wards ( 3 students). All the patients and students were native English speakers, with the exception of two students whose spoken English was near native fluency. The observations and audio-recordings were undertaken during students' four week clinical placement, in which clinicians give daily formative feedback and formal summative feedback at 2 weeks and at the end of the placement.

Phase two: procedure

The researcher audio-recorded the student-patient interaction and the feedback session with the student and supervi- sor in which the interaction with the patient was discussed. The interaction with the patient was audio-recorded in order to contextualise the feedback session; however, this was not included in the thematic analysis of the feedback unless the supervisor gave feedback to the student during the interaction with the patient.

Phase two: analysis

Audio-recordings of student-patient interactions were reviewed to identify feedback on communication during the student-patient feedback interactions. Any identified instances of feedback were transcribed. The feedback sessions with the supervisor and students were transcribed and reviewed by a second researcher not present when the audio-recording took place. If aspects of the feedback were unclear to the second researcher, the first researcher reviewed the audio-recorded interaction and added notes to the transcribed feedback elucidating any contextual features. Transcripts were then analysed and instances of feedback about the student's communication identified and highlighted. Thematic content analysis was undertaken independently by two researchers to identify the emerging themes in the feedback on aspects of communication. Once initial themes had been identified, the two coders compared findings, revisiting the coding schema and analysis as well as comparing findings with those from the workshop data. The findings for the student feedback were then added to the findings for the workshop data.

Table 1. Participants, data, and analytical procedure

\begin{tabular}{|c|c|c|}
\hline Method & Phase 1: workshops & $\begin{array}{l}\text { Phase 2: supervisor } \\
\text { feedback to students }\end{array}$ \\
\hline Participants & $\begin{array}{l}7 \text { physiotherapy educators at } \\
\text { university workshop (Referred to } \\
\text { as PHY WK1) } \\
5 \text { physiotherapy clinical supervi- } \\
\text { sors at hospital based workshop } \\
\text { (Referred to as PHY WK2) }\end{array}$ & $\begin{array}{l}16 \text { final year physiother- } \\
\text { apy students } \\
11 \text { supervisors; } 11 \\
\text { patients. (Referred to as } \\
\text { HOSP FB1) } \\
\text { End-of-term feedback for } \\
7 \text { students from } 3 \\
\text { supervisors. (Referred } \\
\text { to as HOSP FB2) }\end{array}$ \\
\hline $\begin{array}{l}\text { Triggers/ } \\
\text { interactions } \\
\text { for feedback; } \\
\text { setting }\end{array}$ & $\begin{array}{l}3 \text { videos of student-patient } \\
\text { interactions; } 1 \text { student from non- } \\
\text { English speaking background. } \\
\text { Patient conditions: } 44 \text { year old } \\
\text { male (simulated patient) with } \\
\text { chronic back pain; } 89 \text { year old } \\
\text { woman in rehabilitation from } \\
\text { stroke; male patient who had } \\
\text { suffered a stroke and was in a } \\
\text { wheelchair in rehabilitation (age } \\
\text { not available) }\end{array}$ & $\begin{array}{l}\text { Cardiothoracic and } \\
\text { neurology wards, the } \\
\text { outpatient clinic, } \\
\text { rehabilitation clinic and } \\
\text { gymnasium }\end{array}$ \\
\hline Data & $\begin{array}{l}\text { Audio-recordings of workshops; } \\
\text { notes from participants }\end{array}$ & $\begin{array}{l}\text { Audio-recordings of } \\
\text { supervisors feedback to } \\
\text { students; audio- } \\
\text { recordings of student- } \\
\text { patient interactions }\end{array}$ \\
\hline $\begin{array}{l}\text { Analytical } \\
\text { procedure }\end{array}$ & $\begin{array}{l}\text { Thematic analysis of transcrip- } \\
\text { tions of audio-recorded workshop } \\
\text { data. Checking of participant } \\
\text { workshop notes to clarify any } \\
\text { information in audio-recording. }\end{array}$ & $\begin{array}{l}\text { Thematic analysis of } \\
\text { transcriptions of } \\
\text { feedback. Cross- } \\
\text { checking with audio- } \\
\text { recorded interaction of } \\
\text { patient/student interac- } \\
\text { tion for contextual } \\
\text { information to clarify } \\
\text { feedback if needed. }\end{array}$ \\
\hline
\end{tabular}


At this point, one researcher (JP) refined the overall number of themes. An overview of the participants, data, and analytical procedure for both phases is shown in Table 1 .

\section{Results}

There was little discernible difference in the content of the feedback between the workshop and the hospital setting; the most noticeable difference was the in the amount of feedback provided. That is, the clinical supervisors infrequently mentioned communication in their feedback.

Thematic analysis revealed that physiotherapy educators and supervisors shared values on what constitutes effective student-patient communication. We identified five major themes in the findings from both phases. These themes are non-verbal communication, manner, language, content and organisation, and interactional tools. These themes are defined and exemplified below. To aid the description of the findings, the five themes have been grouped into two superordinate categories: i) generic communication skills in the clinical setting, and ii) clinical skills necessary to facilitate gathering information and management. The category 'generic communication skills' encompasses the themes of non-verbal communication, manner, and language; the category 'clinical skills' encompasses content and organisation (gathering information, developing a management plan, organization), and interactional tools. A summary of the five themes is provided in Table 2.

Table 2. What physiotherapy educators value in communication

\begin{tabular}{ll}
\hline Generic communication skills & $\begin{array}{l}\text { Clinical skills used for gathering infor- } \\
\text { mation and management }\end{array}$ \\
\hline - Non-verbal communication & - Content and organisation \\
- Manner & - gathering information \\
- Language & - developing a management plan \\
& - organisation \\
\hline
\end{tabular}

\section{Generic communication skills in the clinical setting}

\section{Non-verbal communication}

The theme of non-verbal communication refers to feedback relating to eye contact; facial expression; posture and movement of head, limbs and body; and non-lexicalised sounds such as umm.

Table 3. Examples of the theme non-verbal communication

\begin{tabular}{ll}
\hline Examples [+] & Examples [-] \\
\hline $\begin{array}{l}\text { "His eye contact and body } \\
\text { language was reasonably good" } \\
\text { [PHY WK1] }\end{array}$ & $\begin{array}{l}\text { "But at times it was really not } \\
\text { quite appropriate smiling" [PHY } \\
\text { WK1] }\end{array}$ \\
$\begin{array}{ll}\text { "So there was evidence with his } \\
\text { nodding"[PHY WK1] }\end{array}$ & $\begin{array}{l}\text { "He didn't even look at her a lot of } \\
\text { the time"[PHY WK1] }\end{array}$ \\
$\begin{array}{ll}\text { "And she was kinda leaning into } \\
\text { the patient more"[PHY WK2] }\end{array}$ & $\begin{array}{l}\text { "The therapist was only just kind } \\
\text { of giving yes' and nods"[PHY } \\
\text { WK1] }\end{array}$ \\
\hline
\end{tabular}

Non-verbal communication was evaluated both positively and negatively. Not enough or too much of a particular behaviour, for example smiling, was also evaluated negatively (Table 3). To interpret the positive or negative evaluation of non-verbal communication, it was necessary to refer to the context of the evaluation and the appraisal of other behaviours and actions. For example in the above cited nonverbal behaviour, kind of giving 'yes' and nods, was coded negatively as the student was criticised for only showing minimal interest and not listening sufficiently to the patient.

\section{Manner}

The theme of manner refers to attitudes and behaviours towards the patient of engagement, rapport, empathy, selfpresentation, and verbal encouragement. Examples are shown in Table 4 below.

Table 4. Examples of the theme manner

\begin{tabular}{ll}
\hline Examples [+] & Examples [-] \\
\hline "So, respectful, asking what & "He came across as a bit. slipshod, a bit \\
the patient would prefer to be & casual..." [PHY WK1] \\
called" [PHY WK2] & \\
"She's quite warm, really & "He just looked to me to be quite uncom- \\
warm, good rapport, friendly" & fortable" [PHY WK1] \\
[PHY WK2] & \\
"The second student was & "When you're getting him up and walking, \\
more relaxed and was & you probably just need to be a little more \\
interacting in a more relaxed & $\begin{array}{l}\text { directive and bit more authoritative." } \\
\text { way" [PHY WK2] }\end{array}$ \\
& "SoSP I guess a bit condescending I guess in \\
& $\begin{array}{l}\text { that respect, once again it wasn't modified } \\
\text { to her" [PHY WK1] } \\
\text { "But what came across to me is age } \\
\text { inappropriate lack of respect and his } \\
\text { behaviour and attitude to someone that } \\
\text { age, really" [PHY WK1] }\end{array}$ \\
\hline
\end{tabular}

Participants valued behaviours that contributed to students interacting with patients with confidence and maturity and treating patients respectfully. Utterances coded as belonging to the theme of manner often co-occurred with coding for the theme non-verbal communication. That is, non-verbal actions such as nodding, leaning in towards the patient or smiling contributed to a positive assessment of manner, for example:

"I thought his nodding and 'yes' and noise -wasn't so bad in trying to provide a bit of empathy with the patient." [PHY WK1]

Negative examples of non-verbal communication were also discussed in the context of a less than engaging manner as in the following example.

"I don't think he looked and took this person into account. You know, she was a lovely old lady who would love to... She was dying to engage. She would've talked about everybody else, her grandchildren probably, or anything else, but he didn't, he didn't even look at her a lot of the time. You know, he'd say 'oh yes'or something...." [PHY WK1] 
The participants not only discussed aspects of the participant's behaviour towards the patient as in the above example ("he didn't even look at her"); they also commented on the impact of the participant's manner on the patient. For example in the excerpt below, the participants allude to the negative consequences of problematic manner in the context of the collaborative professional relationship:

“... (showed) a lack of confidence that perhaps a, a patient might pick up on." [PHY WK2]

"I don't think he had any of that sort of engagement which I would've liked to have seen, 'cause if I'd been her, I wouldn't be doing anything for him." [PHY WK1]

\section{Language}

The theme 'language' refers to comments made about student's language choices, include slang and jargon. Positively evaluated aspects included plain, clear language choices. As can be seen from the excerpts in Table 5 below, the participants themselves identified the 'theme' language in their responses.

Table 5. Examples of the theme language

\begin{tabular}{|c|c|}
\hline Examples [+] & Examples [-] \\
\hline $\begin{array}{l}\text { "and tried to use some simple } \\
\text { language to explain things } \\
\text { like, initially said the word } \\
\text { 'superficial' but then kinda said } \\
\text { 'on the surface of the skin' and } \\
\text { tried to, you know, bring it } \\
\text { more to the patient's level." } \\
\text { [PHY WK1] }\end{array}$ & $\begin{array}{l}\text { "He probably overused the 'so' at } \\
\text { the beginning of every question } \\
\text { and the 'okay', just too many times } \\
\text { (xxxx) he'd heard. And, the } \\
\text { wording occasionally wasn't as } \\
\text { good as I thought, okay." [PHY } \\
\text { WK1] }\end{array}$ \\
\hline \multirow[t]{2}{*}{$\begin{array}{l}\text { "I thought she used the plain } \\
\text { language quite well." [PHY } \\
\text { WK2] }\end{array}$} & $\begin{array}{l}\text { "I would've liked him not to use } \\
\text { language like there were lots of } \\
\text { 'ums','cool'[PHY WK1] }\end{array}$ \\
\hline & $\begin{array}{l}\text { "The question such as 'have you } \\
\text { got steps or anything?' you know, } \\
\text { that sort of, what the hell is } \\
\text { 'anything' you know?" [PHY WK1] }\end{array}$ \\
\hline
\end{tabular}

\section{Clinical skills for gathering information and management}

The superordinate category 'clinical skills for gathering information and management' encompasses the two themes of 'content and organisation' and 'interactional tools'. These themes refer to techniques that the educators and supervisors valued for gathering clinical and psychosocial information in order to make a clinical diagnosis and formulate an appropriate management plan.

\section{Content and organisation}

This theme refers to students' demonstration of clinical knowledge and understanding through depth of questioning and coverage of the clinical issues and demonstration of clinical reasoning. It incorporates strategies to organise and elicit information and propose a management plan, including signposting. The theme 'content and organisation' has three sub-themes. The first two sub-themes correspond to essential clinical tasks of the physiotherapy clinician-patient interaction as identified by the participants: that is i) gathering information, and ii) developing a management plan. 'Gathering information' refers to comments supervisors made about students' eliciting of the presenting problem. These comments include assessment of the patient's functionality and management of tasks of daily living as well as the patient's concerns, and treatment goals. The participants evaluated the fulfilment of some tasks in terms of comprehensiveness or completeness. Participants also discussed the need to prioritise information. 'Developing a management plan' refers to engaging the patient in the management plan as well as patient education in relation to the management plan. The third sub-theme is 'Organisation' and refers to the cohesiveness, fluency and overall structuring of the interview. Table 6 gives examples from the three sub-themes of content and organisation.

Table 6. Examples of the theme content and organisation

Content and organisation: gathering information

"And he also wasn't clear, even though he'd sort of got a lot of information, maybe that's the main bit that he missed, is he didn't actually know what his main problem was. "[PHY WK1]

"Good to examine functional state, things like that."[PHY WK1]

"He investigated the aggravating factors and sort of lacked I guess a little bit specifics and what he would objectively use to re-evaluate later on." [PHY WK1]

"And the technicality wasn't there enough to enable him to therefore perform an appropriate or efficient or effective analysis. The main thing is he just didn't have enough information to allow him to go further. "[PHY WK2]

'She said 'okay, you've had this stroke,' didn't actually ask about his current function and what effects it's had and um change pre- to post morbid. "[PHY WK2]

Content and organisation: developing a management plan

"I thought it was good that he was working towards establishing goals with her." [PHY WK1]

"And I think you know if you came to a bedside um after l'd had surgery and you explained why you were there and you know what the benefits were of what you were delivering. "[HOSP FB1]

Content and organisation: organisation

"Yeah, I think there was definitely a lack of structure and, sort of preplan-
ning of why he was actually talking to this lady." [PHY WK1]
"I thought she went with the patient's flow quite well which is a nice way,
rather than answering, I mean asking off a sheet, she: she followed her
cue: the cue of the patient, went with that, and I think as long as overall
you get all the main information it doesn't matter too much about order if
you can keep the flow." [PHY WK2]

\section{Interactional tools}

The final theme is interactional tools. Interactional tools encompass linguistic strategies that the students utilised to conduct and manage the interview as well as to engage the patient in the unfolding interaction. It includes chunking strategies such as summarising information; clarifying strategies such as checking, rephrasing, asking for clarification; and questioning strategies such as asking open-ended questions, and avoiding leading questions. The excerpts below include positive and negative examples, which are indicated by $[+]$ for a positively valued tool, and [-] for negative behaviours or when a strategy was omitted. The first example, from the hospital setting, was couched as a recommendation to the student of what she ought to do. 
The context of this recommendation about organising information and providing structure for the patient was to aid the patient's understanding, hence the coding as 'interactional'; however, 'do a little summary' impacts on overall organisation of the interview.

Table 7. Examples of the theme interactional tools

"You expect your students at the end of a history taking sequence to have a phase in the sequence to say, 'well so you've come in because of blah blah blah," so do a little summary...' [HOSP FB2]

"I felt that a lot of the time he was leading his questions. Um, so he'd say, 'your knee's getting sore, ' 'it's manageable,' and, the patient I don't think really had actually, you know, if you those - ask an open question you might not have come to that conclusion so ah I felt a lot of his questionings were led as statements that the patient was boxed into agreeing with or, looking silly, "[PHY WK2][-]

"His use of clarifying and paraphrasing throughout, oh, a few times, sort of that he understood the patient" [PHY WK1]

"Again not really redirecting the patient if the answer wasn't really answering what the therapists wanted- was asking about, he just kind of let it let it run, and then moved on to the next question. "[PHY WK2][-]

\section{Interrelationships between the themes}

The five major themes of non-verbal communication, manner, language, content and organisation, and interactional tools have been presented as belonging to distinct categories; however, these themes co-occurred and were codependent in the data. Positively evaluated non-verbal communication in some instances occurred with positively evaluated manner; inefficient questioning [interactional tools] impacted on organisation [content and organisation]. This overlap and interdependence of the themes is alluded to by the participants during the workshop held at the university, where at one point in the discussion, the participants noted the difficulty of separating the communication from the clinical tasks and knowledge.

Participant 1 It's like whether we're talking about communication or treatment strategy...cause it's ...yeah

Participant 2 And that becomes a challenge, isn't it

Participant 3 You can't really separate the two

\section{Comparison of the findings with the Australian physio- therapy standard 2.1}

The five themes of non-verbal communication, manner, language, content and organisation, and interactional tools are broad in scope. It is possible to map these themes onto the equally broad sub-domain of the Australian physiotherapy standard 2.1, communicate effectively with the client. The proposed relationship of the five themes identified in this study to the components of the sub-domain of 2.1 is shown in Table 8. As is shown in the table, the two clinical skills themes, 'content and organisation' and 'interactional tools', as well as 'language apply broadly to various elements of the standard 2.1, particularly the components 2.15-2.18. These components provide no guidance as to how these communication tasks are to be achieved. The themes elaborate the multifaceted nature of the tasks, that is, approach, knowledge, organisation, and necessary language. However, it is the exemplification of the themes through the supervisor and educator feedback provided above on actual student-patient interactions that has the greater explanatory power for educators and students. This is discussed below.

Table 8. Elements of Australian physiotherapy standard 2.1 broadly matched against themes identified in the data

\begin{tabular}{|c|c|}
\hline $\begin{array}{l}\text { Australian physiotherapy standard } 2.1 \\
\text { communicate effectively with the client }\end{array}$ & identified in the data \\
\hline Rapport is established with the client & manner \\
\hline $\begin{array}{l}\text { Verbal and non-verbal communication is } \\
\text { adapted to the needs and profile of the } \\
\text { client }\end{array}$ & $\begin{array}{l}\text { language; non-verbal } \\
\text { communication }\end{array}$ \\
\hline $\begin{array}{l}\text { Communication with the client is conducted } \\
\text { in a manner and environment that ensures } \\
\text { confidentiality, privacy and sensitivity }\end{array}$ & manner \\
\hline $\begin{array}{l}\text { The goals, nature, purpose and expected } \\
\text { outcomes of the physiotherapy intervention } \\
\text { are discussed and agreed }\end{array}$ & $\begin{array}{l}\text { content and organisation; } \\
\text { interactional tools }\end{array}$ \\
\hline $\begin{array}{l}\text { Appropriate techniques are used to } \\
\text { communicate effectively with the client } \\
\text { about health promotion issues relevant to } \\
\text { the area of physiotherapy practice }\end{array}$ & $\begin{array}{l}\text { content and organisation; } \\
\text { interactional tools; } \\
\text { language }\end{array}$ \\
\hline $\begin{array}{l}\text { Where communication barriers exist efforts } \\
\text { are made to communicate in the most } \\
\text { effective way possible and assistance is } \\
\text { sought as required from sources including } \\
\text { technology and other persons }\end{array}$ & ditto \\
\hline $\begin{array}{l}\text { Communication is adapted to accommodate } \\
\text { client needs }\end{array}$ & ditto \\
\hline $\begin{array}{l}\text { Appropriate strategies are employed to } \\
\text { address communication difficulties }\end{array}$ & ditto \\
\hline
\end{tabular}

\section{Discussion}

The educators and clinical supervisors attended to numerous aspects of communication in the workshop data, where they were directed to focus on the communication skills. Discussion of clinical aspects such as the assessment of mobility and function of patients was intrinsic to the educators' feedback although the focus was on communication skills. In the hospital feedback setting with students, there was less emphasis on communication skills, and less breadth in the aspects of communication mentioned. There was more emphasis on content knowledge and clinical skills, particularly in regards to treatment. We have adopted the term 'skill' in the superordinate categories of 'generic communication skills' for non-verbal communication, manner, and language; and 'clinical skills for gathering communication and management' for content and organisation, interactional tools; however, the 'skill' label only partly captures the knowledge, behaviours, actions and strategies that contribute to these domains as is evident in the findings. Differences between workshop sessions and hospital feedback sessions on the focus on communication could relate to a greater emphasis placed on knowledge and clinical skills when students are positioned in clinical settings.

The five major themes of non-verbal communication, manner, language, content and organisation, and interac- 
tional tools resonate with existing physiotherapy communication literature $\mathrm{e}^{14,15}$ although there was little emphasis on involving patients in decision making. This aspect may be to do with the students' limited clinical experience. Also, negotiating treatment plans with patients may be a higher order communication skill practised by more experienced therapists. The excerpts quoted in the previous section demonstrate the educators and supervisors' orientation to a patient-centred approach to physiotherapy healthcare. ${ }^{15}$ Themes such as manner, non-verbal communication and interactional tools highlight the importance of good communication for establishing a therapeutic relationship in which the patient works with the therapist to achieve treatment goals. ${ }^{1}$ The participants in this study did not directly comment on clinical reasoning although communicating clinical reasoning to patients is considered an important aspect of effective communication; ${ }^{17}$ instead the extent of students' clinical knowledge was seen to impact on the types of questions the students asked (theme: content and organisation), but was not linked to sharing with the patient the type of diagnosis the student therapist was in the process of formulating.

The study also sought to exemplify the Australian physiotherapy standards, which, as noted above, offer only a very broad characterisation of what communication skills are expected in professional practice. As the focus of this study was communication between patients and students rather than inter and intraprofessional communication between and among health professionals, the findings of this study relate to the sub-domain of communicate effectively with the client (2.1). The findings show that the realisation of this sub-domain involves interrelated behaviours and skills rather than discrete skills as the description of the communication strategies in the standards imply. Furthermore, the educators' feedback on the performance of students with different patients presenting with complex psycho-social considerations, highlighted the importance of teasing out what is involved in 'adapting communication styles' depending on the patients' age, health, and functional abilities. Table 8 shows how the themes that emerged from the study map onto the physiotherapy communication. The examples of contextualised feedback can be used to exemplify what is implied by the abstract behaviours and tasks listed in the standards. While the highly general nature of the physiotherapy standards means that they can be applied across all contexts, they offer no tangible insight into what constitutes effective communication and what adapting one's communicative style to the patient entails. The current study has tapped a previously unexplored source of evidence that can inform standard setting and curriculum development by providing a rich and contextualized picture of the valued communication skills, attitudes and behaviours of physiotherapy graduates and, conversely, the features of communication that are not deemed appropriate by professionals with experience of both clinical practice Int J Med Educ. 2012;3:166-174 and training. The examples of contextualized feedback presented in this paper can be used in tandem with the physiotherapy standards to help trainees make sense of what the profession values in clinical communication and accordingly, what they might aspire to. These examples can also inform assessment decisions on the adequacy of particular performances with respect to the standards.

We believe this kind of bottom-up empirically based approach to describing communication skills holds promise; however, we must also acknowledge the study's limitations as far as the range and number of stimuli used to generate feedback were concerned: for example, all the patients were native speakers of English and therefore do not represent the diversity of the real world clinical setting. Further research is needed to test the proposed themes with a more diverse sample of educators, patients, and students and to build up a more comprehensive and nuanced picture of what is needed for effective communication in physiotherapy. Furthermore, a future area of study is to determine what aspects of effective communication are unique to physiotherapy practice and what aspects are fundamental to all health professionals. Teasing out these factors will contribute to better understandings of effective physiotherapy communication and can inform targeted communication skills teaching for physiotherapy students.

\section{Acknowledgments}

The authors wish to acknowledge the participation of the students, patients, clinical supervisors and educators who participated in the research. This project was funded by an Australian Research Council Linkage Grant (LP0991153) with matching funding from the Occupational English Test Centre.

\section{Conflict of Interest}

The authors declare that they have no conflict of interest.

\section{References}

1. Tyson S, Turner G. Discharge and follow-up for people with stroke: what happens and why. Clin Rehab. 2000;14:381-92.

2. National Health and Medical Research Council. Communicating with patients: advice for medical practitioners. Canberra: Australian Government; 2004

3. Hills R, Kitchen S. Satisfaction with outpatient physiotherapy: focus groups to explore the views of patients with acute and chronic musculoskeletal conditions. Physio Theory Pract. 2007;23(1):1-20.

4. Health Care Complaints Commission. 2010-2011 annual report. Sydney: New South Wales Government. 2011[cited 2012 August 1]; Available from: http://www.hccc.nsw.gov.au/Publications/AnnualReports/default.asx. 5. Australian Institute of Health and Welfare. Sentinel events in Australian public hospitals 2004-05. Canberra: Australian Institute of Health and Welfare; 2007.

6. Neale G, Woloshynowych M, Vincent C. Exploring the causes of adverse events in NHS hospital practice. J R Soc Med. 2001;94(7):322-30.

7. Hawthorne L, Minas H, Singh B. A case study in the globalization of medical education: assisting overseas-born students at the University of Melbourne. Med Teach. 2004;26:150-9.

8. Barton D, Hawthorne L, Singh B, Little J. Victoria's dependence on overseas trained doctors in psychiatry. People and Place. 2003;11(1):54-64.

9. Prideaux D. Cultural identity and representing culture in medical education: who does it? Med Educ. 2001;35:186-7. 
10. Mullan F. The metrics of the physician brain drain. N Engl J Med. 2005;353(17):1810-8.

11. Bialocerkowski A, Wells C, Grimmer-Somers K. Teaching physiotherapy skills in culturally-diverse classes. BMC Medical Education. 2011;11:1134.

12. Garling P. Acute care services in NSW public hospitals. Sydney: NSW Government; 2008.

13. Jaggi A, Bithell C. Relationships between physiotherapists' level of contact, cultural awareness and communication with Bangladeshi patients in two health authorities. Physiotherapy. 1992;81(6):330-7.

14. Trummer U, Mueller U, Nowak P, Stidl T, Pelikan J. Does physicianpatient communication that aims at empowering patients improve clinical outcome? A case study. Patient Educ Counsel. 2006;61:299-306.

15. Resnik L, Jensen G. Using clinical outcomes to explore the theory of expert practice in physiotherapy. Physical Therapy. 2003;83(12):1090-106

16. Parry RH. Communication during goal-setting in physiotherapy treatment sessions. Clin Rehab.2004;18(6):668-82.

17. Ajjawi R, Higgs J. Core components of communication of clinical reasoning: a qualitative study with experienced Australian physiotherapists. Ad Health Sci Educ. 2012;17:107-19.

18. Parry R, Brown K. Teaching and learning communication skills in physiotherapy: What is done and how should it be done? Physiotherapy. 2009;95:294-301.

19. von Fragstein M, Silverman J, Cushing A, Quilligan S, Salisbury H, Wiskin C. UK consensus statement on the content of communication curricula in undergraduate medical education. Med Educ. 2008;42:1100-7.

20. Brown J. How clinical communication has become a core part of medical education in the UK. Med Educ. 2008;42:271-8.

21. Makoul G. The SEGUE framework for teaching and assessing communication skills. Patient Educ Counsel. 2001;45(1):23-34.

22. Rider E, Hinrichs M, Lown B. A model for communication skills assessment across the undergraduate curriculum. Med Teach. 2006;28(5):e127-e34.

23. Institute for International Medical Education. Global minimum essential requirements in medical education. Med Teach. 2002;24(2):130-5.

24. Australian Medical Council. AMC assessment and accreditation of medical schools: standards and procedures. 2009 [cited 2010 March 10];
Available from: http://www.amc.org.au/images/Medschool/standards.pdf. 25. Graham I, Gleason A, Keogh G, Paltridge D, Rogers I, Walton M, et al. Australian curriculum framework for junior doctors. MJA. 2007;186(7 Suppl):S14-S9.

26. The Physiotherapy Board of New Zealand. Physiotherapy competencies for physiotherapy practice in New Zealand. 2009[cited 2012 August 1]; Available from: http://www.physioboard.org.nz/docs/PHYSIO_Compete ncies_09_for_web.pdf.

27. Chartered Society of Physiotherapy. Core standards of physiotherapy practice. United Kingdom. 2010[cited 2012 August 1]; Available from: http:// www.csp.org.uk/publications/core-standards-physiotherapy-practice. 28. Australian Physiotherapy Council. Australian standards for physiotherapy. Canberra. 2006 [cited 2012 August 1]; Available from: http ://www.physiocouncil.com.au/files/the-australian-standards-for physiotherapy.

29. Haidet P, Dains J, Paterniti D, Hechtel L, Chang T, Tseng E, et al Medical students' attitudes towards the doctor-patient relationship. Med Educ. 2002;36:568-74

30. Malhotra A, Gregory I, Darvill E, Goble E, Pryce-Roberts A, Lundberg $\mathrm{K}$, et al. Mind the gap: learners' perspectives on what they learn in communication compared to how they and others behave in the real world. Patient Educ Counsel. 2009;76:385-90.

31. Liddell M, Koritsas S. Effect of medical students' ethnicity on their attitudes towards consultation skills and final year examination performance. Med Educ 2004;38:187-98.

32. Go S, Richards DM, Watson WA. Enhancing medical student consultation request skills in an academic emergency department. J Emerg Med. 1998;16(4):659-62.

33. Elder C, Pill J, Woodward-Kron R, McNamara T, Manias E, McColl E, et al. Health professionals' views of communication: implications for assessing performance on a health-specific English language test. TESOL Quarterly. 2012.

34. Jacoby S, McNamara. Locating competence. English for specific purposes. 1999;18(3):213-41.

35. Woodward-Kron R, Stevens M, Flynn E. The medical educator, the discourse analyst, and the phonetician: a collaborative feedback methodology for clinical communication. Acad Med. 2011;85(5):565-70. 